\title{
Electrochemical Immune Analysis System for Gastric Cancer Biomarker Carcinoembryonic Antigen (CEA) Detection
}

\author{
Zhenggui Tao, Jinghu Du, Yu Cheng and Qingfeng $\mathrm{Li}^{*}$ \\ Xiangyang Central Hospital Affiliated to Hubei University of Arts and Science, Xiangyang, Hubei, \\ 441021, P.R. China \\ *E-mail: liqfeng@hotmail.com
}

doi: $10.20964 / 2018.02 .21$

Received: 12 October 2017 / Accepted: 23 November 2017 / Published: 28 December 2017

\begin{abstract}
In the present work, carcinoembryonic antigen (CEA), a significant biomarker in gastric cancer diagnostics, was successfully detected by a desirably selective and sensitive electrochemical aptasensor with an electrocatalyst and nanocarrier, i.e., Pt/Au-diaminonaphthalene (DN)-graphene. The developed bioconjugate was captured onto the surface of the electrode via a "sandwich" strategy during the detection of CEA. The proposed method was demonstrated to be sensitive, as indicated by the improved electrochemical response, since the dendritic Pt/Au/DN-graphene showed peroxidasemimic activity for the reduction of $\mathrm{H}_{2} \mathrm{O}_{2}$ introduced into the electrolytic cell, thereby confirming its desirable catalysis capacity.
\end{abstract}

Keywords: Sandwich immunosenso; Carcinoembryonic antigen; Biomarker; Electrochemical determination; Pt/Au nanocomposite

\section{FULL TEXT}

(C) 2018 The Authors. Published by ESG (www.electrochemsci.org). This article is an open access article distributed under the terms and conditions of the Creative Commons Attribution license (http://creativecommons.org/licenses/by/4.0/). 